\title{
Assessment of the Ecological Condition of Soil Cover Based on Remote Sensing Data: Erosional Aspect
}

\author{
Andrii Achasov ${ }^{1 *}$, Alla Achasova ${ }^{2}$, Ganna Titenko ${ }^{1}$, Oleg Seliverstov ${ }^{1}$ and Vladimir Krivtsov ${ }^{3}$ \\ ${ }^{1}$ V.N. Karazin KhNU, School of Ecology, 61022 Kharkiv, Ukraine \\ ${ }^{2}$ NSC «O.N. Sokolovsky ISSAR», Soil Erosion Control Laboratory, 61024 Kharkiv, Ukraine \\ ${ }^{3}$ Royal Botanic Garden Edinburgh, EH3 5LR Edinburgh, United Kingdom
}

\begin{abstract}
Soil erosion by water is the most important global environmental problem. A modern system for assessing and monitoring soil erosional degradation should be based on the use of remote sensing data. This raises the issue of correct data decoding. The article proposes a method for visual interpretation of eroded soils according to the Sentinel image obtained in the visible range. The authors give some combinations of decoding signs to determine the manifestations of linear and surface water erosion from images. The article shows possible errors in decoding the manifestations of water erosion and gives an example of assessing the erosion of the soil cover based on the results of decoding the Sentinel-2 satellite image. Moderately and heavily eroded soils are reliably distinguished, the area of which, according to the interpretation data, was $2.4 \%$ of the area of arable land in the studied territory. In the future, the obtained sample of spectral images of eroded soils can be used to develop an automated method of interpretation based on the principle of "computer vision".
\end{abstract}

\section{Introduction}

Soil erosion by water is a "shadow of world agriculture" according to Professor S.Yu.Bulygin's poetic statement [1]. After all, human agricultural activity has always caused more or less destructive erosion processes everywhere. Erosion is not only a huge environmental problem [2], but also an economic problem estimated at tens of billions of US dollars. Every year, the world loses 33.7 million tons of food due to erosion [ $\underline{3}]$.

Unfortunately, Ukraine is no exception. According to experts, the area of land affected by water erosion in Ukraine is about $40 \%$. Due to this and direct and indirect losses, the country's economy loses up to 10 billion of US dollars annually [1]. Direct negative consequences of soil erosion include the loss of crops, decrease in the harvest quality, and deterioration of infrastructure. However, soil erosion also results in a multitude of less obvious indirect effects, including e.g. disturbance of the local hydrological balance, pollution of local water bodies and smothering of aquatic organisms, among others. The lower lying areas with depositional environment may receive an excessive amount of sediments; that alters their geomorphological settings and decreases the hydraulic conductivity of the surface deposits thus making those areas more prone to flooding and inundation. At the same time, however, higher grounds situated on hillsides tend to experience insufficient water resources due to the increase in surface runoff. Furthermore, erosion processes also contribute to the climatic changes both through the increase in the mineralization of soil organic matter and consequent increased emissions of greenhouse gasses, and through alteration of the radiological balance due to the deterioration of the surface vegetation cover and the accompanying changes in albedo. All the processes listed above have negative implications for the economy and wellbeing of local residents, as well as for the global climate change.

The problem of erosion, like any other problem, requires, first of all, clear understanding of the condition of the country's soil cover and the pace of ongoing erosion processes.

Both issues require the use of modern research technologies, such as geographic information systems and remote sensing of the Earth surface. After all, it is impossible to monitor 32 million hectares of arable land in the country without space survey data [4]. Space sounding data is a reliable basis for monitoring soil resources due to the high detail and visibility of images. Being relatively inexpensive, they can be easily updated [ $[\underline{5}$.

Fortunately, the current development of space observation systems helps to address this issue. At present there are, at least, two programs, providing free space survey data from Landsat and Sentinel satellites. These data, provided by the Sentinel-2A and Sentinel2B spacecrafts, are particularly interesting. Spatial resolution of images in the visible range is $10 \mathrm{~m}$. Two satellites take photos of the same area every 5 days, which is completely suitable for monitoring and mapping of eroded soils [ 6$]$.

\footnotetext{
"Corresponding author: achasov@karazin.ua
} 
It should be noted that space monitoring involves continuous collection of huge amounts of data that need to be analyzed quickly and efficiently. The space image itself is a "semi-finished product". It becomes thematically informative only after instrumental processing by an expert, using special hardware and software, i.e - decoding. The most desirable and difficult is the option of automated decoding of remote sensing data. The computer selects and interprets objects in the image with little human intervention.

There are many examples of attempts to automatically decode the manifestations of water erosion on various scales in the scientific literature. Global forecasts of erosion spread according to satellite data of medium resolution are given in [7].

A previous study [] presented the results of semiautomated decoding of gullies by integrating geographical object analysis of images with modern models of machine learning. For the analysis presented in this paper, we used Sentinel 2A multispectral survey data, a global digital terrain model obtained from ALOS-2 satellite data, and ground-based observation data. Karami and co-authors [9] estimated linear erosion from IRS-P6 satellite images, using pixel-bypixel and object-oriented automated classification methods. In [ $\underline{8}]$ there is an example of successful application of machine learning technology for the recognition of gully erosion. A variant of the method of determining the gully network according to highresolution space sounding (on WorldView imagery) is presented by S. Uchida [10]. Using additional digital elevation data of ASTER / GDEM2, he obtained the recognition accuracy of the gully network of $63.4 \%$. Some approaches to automatic decoding of erosion are also considered in [11]. However, the authors emphasize that "a researcher, analyzing satellite imagery, can often provide more accurate results in determining eroded soils".

It should be noted that most of the publications relate to the definition of linear (gully) erosion. Little attention is paid to the issue of surface water erosion, which is not surprising, given the complexity of decoding this phenomenon. Thus, Žížala, D. et al., 2019 [12] showed that even on a regional scale, the accuracy of automatic selection of eroded areas by uncontrolled classification of images according to Sentinel-2A reached 55.2\%. In comparison, the accuracy of decoding was $86.9 \%$, a remarkable increase considering the fact that only heavily eroded soils are separated from all others with the additional use of visual decoding of images to adjust the results.

Therefore, visual decoding of water erosion is a mandatory step in the development of methods for automatic decoding of images and verification of its results. At the same time, decoding manifestations of erosion according to the satellite imagery has many "pitfalls", conditioned by the difficulty of complete formalization of such features as the shape of the object, its structure, texture, etc.

The purpose of this article is to analyze the features of visual decoding of eroded soils and erosion processes in space images of the visible range.
Clear establishment of such features and creation of a correct method of visual decoding of eroded soils will allow us to move to the next stage - the automation of this process.

\section{Materials and methods}

\subsection{Characteristics of research sites}

The research was carried out in the territory of the forest-steppe physical-geographical zone and the northsteppe physical-geographical subzone of Ukraine at the junction of Kharkiv, Poltava and Dnipropetrovsk regions (Fig. 1) during 2019-2020. The study area was $12058.7 \mathrm{~km}^{2}$, determined by the size of the standard site of the Sentinel-2a spacecraft.

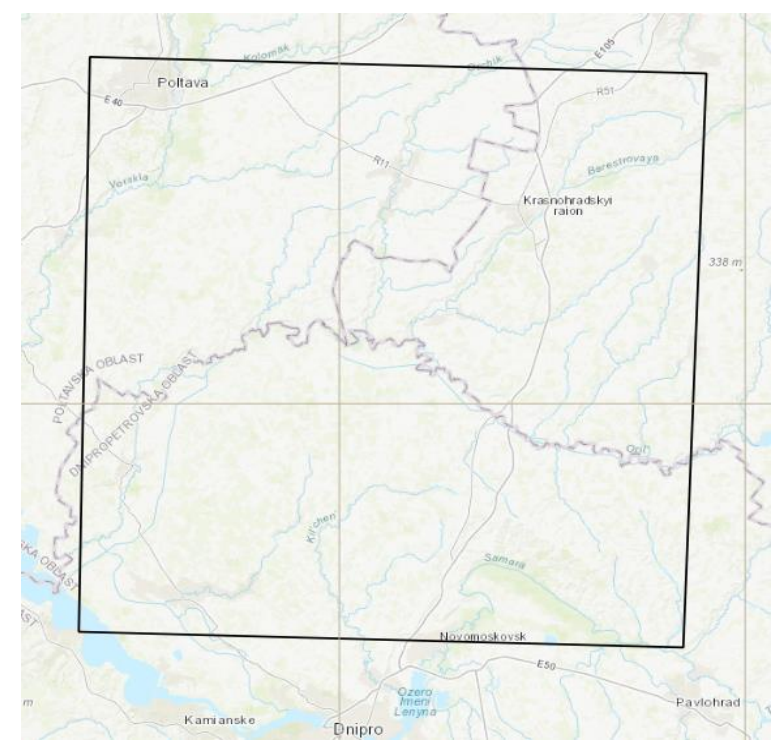

Fig. 1. Map of the research territory

The study area is characterized by a temperate continental climate. The average annual rainfall regularly decreases from northwest to south and southeast in the range of 550-460 mm per year. Its relief is characterized by the alternation of flat watersheds with wide river valleys. Most of the territory is actively used in agriculture. All this contributes to the significant development of water erosion of arable soils.

The soil cover of the territory is represented mainly by typical chernozems, podzolic chernozems and dark gray forest soils. All of them are characterized by a significant content of organic matter in the upper genetic horizon, determining their corresponding color (from gray to dark gray and black-brown) color and is an important feature in the visual decoding of space images.

According to the previous agrochemical studies, the average content of soil humus was quoted as $4,2 \%$ and $3,8 \%$ for Kharkov and Dniepropietrovsk regions respectively [13], whilst for Poltava region it was reported as $3,26 \%$ [14]. These levels of the soil humus content are considered as 'elevated' and 'high' [15], and soil horizons with such humus content are characterized by typical dark colours. Furthermore, 
humus-containing substances of the chernozem soils have a stronger colouring capacity compared to the podzolic soils [16], i.e. chernozem soils appear much darker than podzolic soils with the same organic carbon content.

\subsection{Characteristics of the Remote Sensing Data Used in the study}

A space image taken by the Sentinel-2a on April 27, 2019 (T36UXV_20190427T083601_TCI) was selected for the research. From three channels of the satellite (blue B2, green B3, red B4) the image corresponding to the color image made in the visible range of electromagnetic waves was synthesized.

The main characteristics of the image are: the level of pre-treatment $1 \mathrm{C}$, spatial resolution of $10 \mathrm{~m}$, cloudiness 0 points. The chosen shooting date allowed, on one hand, to observe the largest possible number of fields without cleared vegetation cover, and on the other - to avoid the influence of significant soil moisture after snow melting.

\subsection{Methods of decoding space images}

Visual decoding is the oldest type of decoding, which arose simultaneously with the first attempts to lift a person into the air. Its essence is to identify real-world objects in aerospace images by their characteristics without using any special hardware or software.

Visual decoding was performed according to the classical method, based on the use of direct (geometric, optical and structural characteristics of objects) and indirect (various relationships and interdependencies between the studied objects) decoding features.

"Recognition" of objects is the result of a complex logical-intuitive process that only the human brain is capable of. It is the complexity of formalizing this process that has led to the fact that, despite all modern devices and developed software, visual decoding remains a very effective tool for the remote sensing data analysis.

The image is decoded in GIS QGIS 3.16.1Hannover. The algorithm for decoding planar erosion consists of the following main stages:

1. Pre-processing of a space image, including adjustments to brightness and contrast for the best visual perception of the image.

2. Selection of open ground fields visually or by numerical analysis of NDVI index.

3. Making sure that the soil at the time of survey was in an air-dry state. Checking whether there was any precipitation in the study area at least three or four days before the date of the survey according to the meteorological stations.

4. Taking into account direct decoding features, such as the color of the open ground and the structure of the image, and indirect features - the landscape location of the object, its proximity to river valleys and gullies.
Since the research methodology is the subject of this article, it will be described in more detail in Section 3.

\section{Results and discussion}

\subsection{Decoding of typical erosional features}

It is known that water erosion can be surface and linear. Linear erosion is the result of a significant concentration of water in natural depressions, resulting in the formation of linear soil erosion.

Such blurs are manifested in the image through a set of the following features (Fig. 2):

1) Dendroidal structure of the image. It is known that such a structure is a manifestation of natural processes of water movement in the landscape. At one time, it was the discovery of such structures on the surface of Mars that proved the presence of water currents on its surface in the past [17].

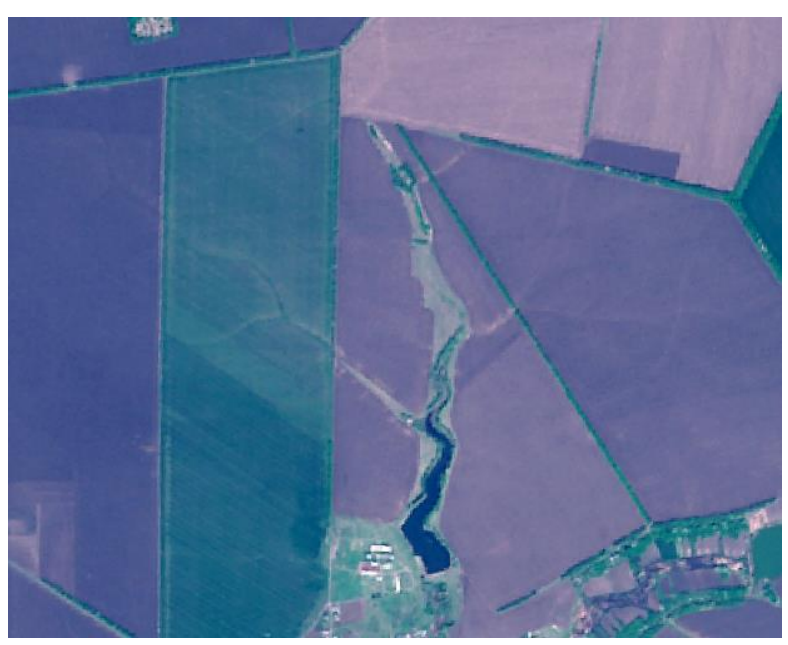

Fig. 2. View of plowed and unplowed linear erosion forms in the space image

2) Color. If linear erosion is of significant size and, therefore, has not been plowed for a long time, the process of its growth slows down, it eventually overgrows with natural vegetation. Accordingly, its color in the images will depend on the species composition and condition of the vegetation in the ravine or gully (Fig. 2). If the erosion has not reached a critical depth that interferes with processing, its color is usually characterized by a combination of light and dark parallel stripes. This is due to the uneven illumination of the opposite slopes of the basin: the light strip is eroded soils on the illuminated slope of linear erosion, and the dark - its shadow slope.

Surface erosion occurs in the case of relatively uniform soil erosion by small streams over the entire surface of the site. Its consequence is the formation of large areas of fairly evenly eroded soils without significant manifestations of linear erosion (Fig. 3).

Diagnosis of planar erosion from space images is also based on a combination of the two above features: color and structure.

1) Color. Spectral properties of soils affected by water erosion have much greater brightness compared 
to unaffected soils. The reason for this is the loss of the upper humus layer and the exposure of the lower soil layers, which have a much lower content of organic matter.

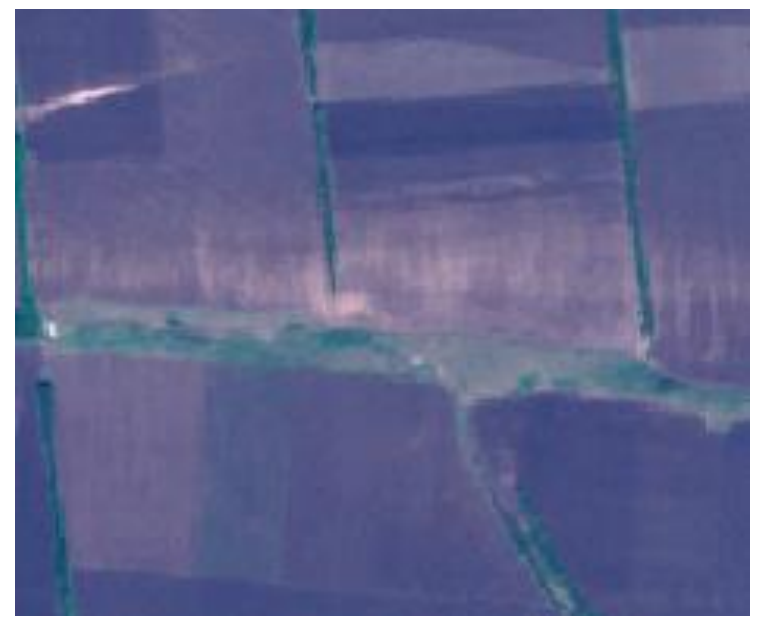

Fig. 3. Manifestations of planar erosion in space images

2) The structure of the image. Clearly expressed dendroidal structures are not typical for surface erosion. Rather, the structure of the image can be called "feathery". Small blurs form a pattern of densely arranged well-oriented, almost parallel light stripes. These stripes are like feathers adjacent to ravines and gullies.

The latter is very important, as the absence of such a topological connection may indicate a misdiagnosis. Therefore, the third decoding feature for surface erosion is topological interdependence.

3) Topological interdependence. This is an indirect decoding feature, connecting small erosions to the clearly defined elements of the ravine-gully network almost at right angles.

\subsection{Decoding of artifact objects}

It is worth emphasizing a very important methodological position - one can select manifestations of any type of water erosion only if there is a combination of these decoding features. Diagnosing soil as eroded by only one feature, such as color, can lead to error. This is especially important when it is impossible to inspect the whole field.

Fig. 4 clearly distinguishes a large area of open light colour ground. However, it would be incorrect to consider this area a manifestation of surface erosion.

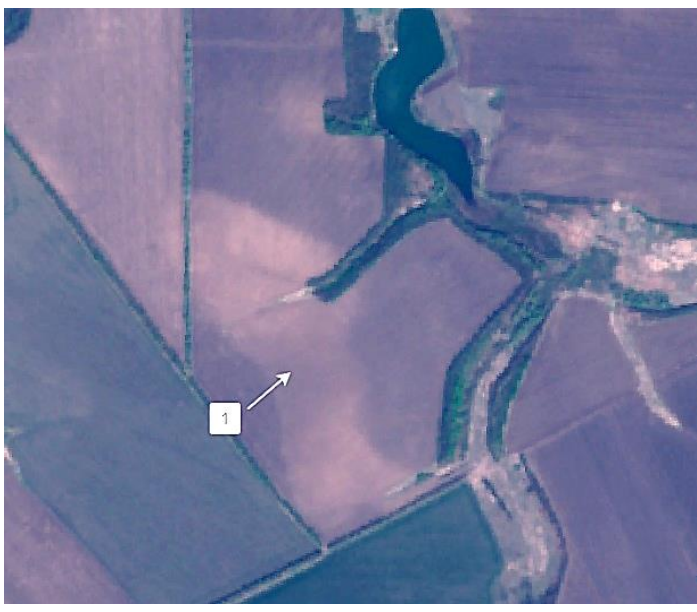

Fig. 4. Possible misdiagnosis of soil erosion (podzolic soils)

Although there are two notable manifestations of linear erosion, there is no feathery structure, characterizing surface erosion.

Looking at the shape of this plot, we can see that it is irregular with smooth twists. Thus, a contour delineating the area with uniform spectral properties is traced on two fields with different cultivation. Therefore, it cannot be considered a result of any agrotechnical measures, visually lightening the surface of the field (for example - leaving straw in the field).

The above-mentioned decoding features are typical for the areas of podzolic soils. These soils are formed under centuries-old forest stands. As a result, their surface horizon has a reduced content of organic matter compared to chernozems and the presence of finegrained quartz (crystalline $\mathrm{SiO}_{2}$ ), which has high reflectivity and gives the soil a characteristic light color. Hence, the picture might be revealing the selection of podzolic soils.

To test this assumption, an archival soil map of scale 1: 25000 was used [18] (Fig. 5).

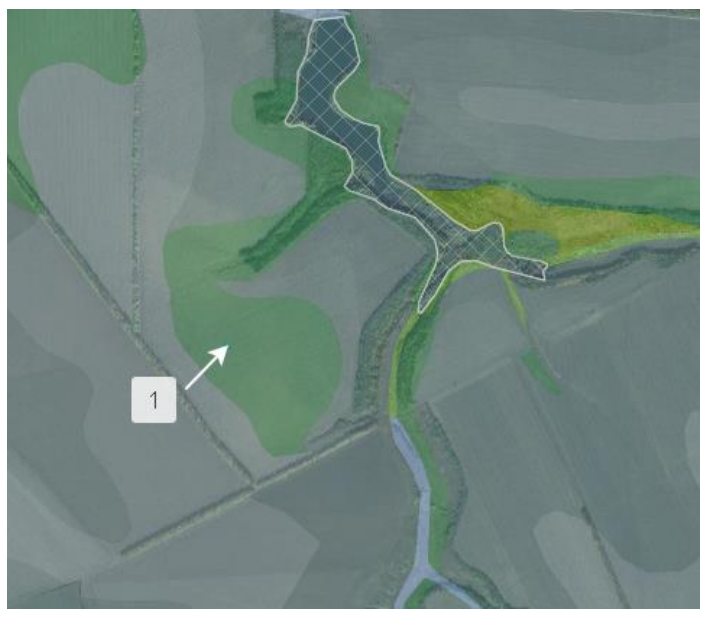

1 - dark-gray podzolic soil

Fig. 5. Overlaying of archival soil map on space image

The light contour, highlighted in the space image shown in Fig. 4, almost completely repeats the section, marked as "Dark gray podzolic and degraded soils and chernozems podzolic and degraded slightly washed heavy loam) on the soil map. Thus, in fact, these are 
not eroded, but podzolic soils bordering on typical chernozems.

An example of possible misdiagnosis of linear erosion is shown in Fig. 6. In this case, the light straight line that passes through the entire image is not an erosive form. First, erosions do not have such clear straight contours. Secondly, the image does not show the dendroidal structure, mandatory for the ravinegully network.

This light line is an indicator of the gas pipeline, laid underground. The soil above the gas pipeline is lighter in color compared to the undisturbed soil. This is because the upper humus and lower, lighter soil horizons and rocks were mixed during the laying and backfilling of the gas pipelines.

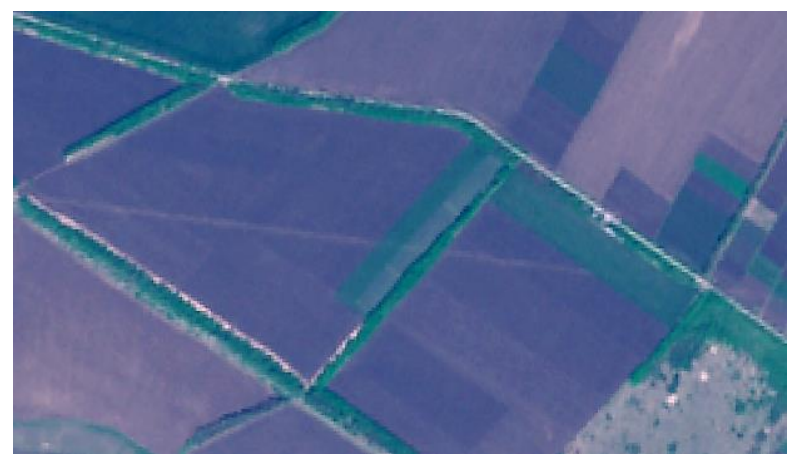

Fig. 6. Anthropogenic linear shapes in space images. Gas pipeline

When decoding, even more difficult situations can arise. Fig. 7 shows a fragment of the image which can be identified as manifestations of linear and surface erosion, as well as the results of human activity, very similar to them.

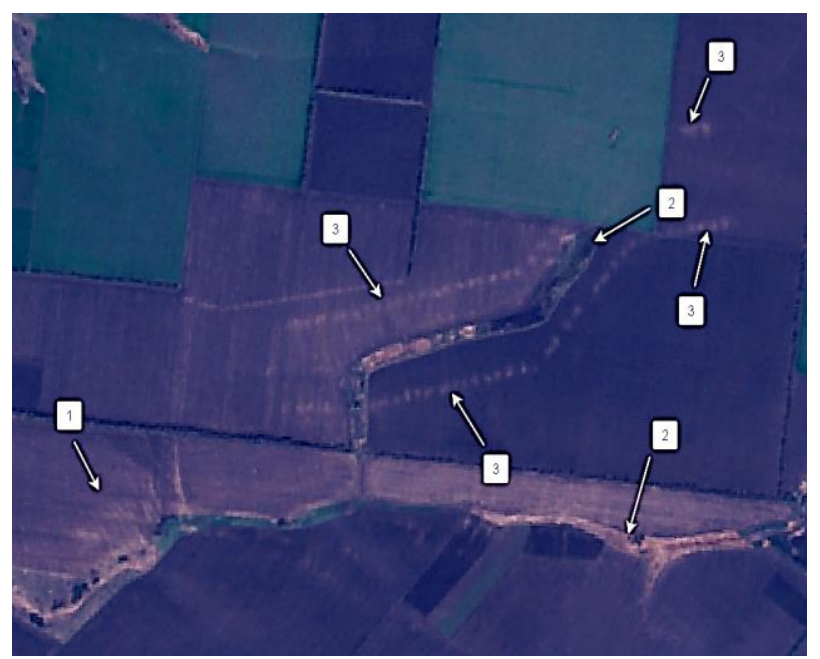

Fig. 7. A fragment of a space image with existing manifestations of erosion and anthropogenic artifacts (Sentinel image 2019)

Number 1 in Fig. 7 is a classic manifestation of surface soil erosion with all its inherent decoding features. The gully network (number 2) is also clearly visible in the picture. However, two light straight lines located on both sides of the ravine appear to be problematic (number 3).

Both lines are formed by separate light rounded spots. The diameter of each spot is $18-20 \mathrm{~m}$. The distance of the lines from the ravine varies between $100-140 \mathrm{~m}$.

Monitoring of this area, using the Internet service GoogleEarth, shows that this phenomenon has been traced unchanged in all available images since 2011 (Fig.8).

It is very difficult to assume that this phenomenon is natural because you can hardly find such clear structures in nature. This phenomenon might be of an anthropogenic origin. It may be related to some land reclamation activities in the area.

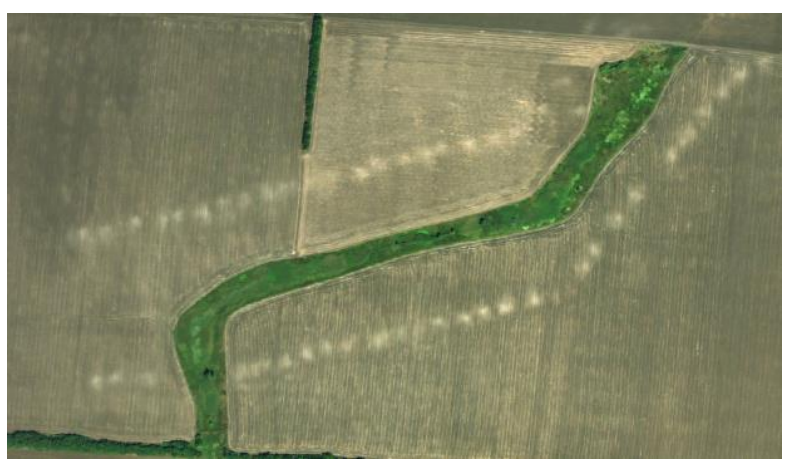

Fig. 8. A snapshot of GoogleEarth 2011. Results of the $x$ visual decoding for a satellite image of the given territory

\subsection{An example of visual decoding the space image}

To improve the accuracy of diagnosis, visual decoding was performed only in fields where there was no vegetation and plant remains. The values of the NDVI coefficient of such fields ranged from 0 to 0.025 . As a result, the total surveyed area was $2,055.3 \mathrm{~km}^{2}$.

Both linear and surface erosions were identified in the area. In such cases, the soils were considered eroded only if the expert was $100 \%$ confident about it. About $10 \%$ of all cases were additionally verified, using the Internet service GoogleEarth (QGIS Send2GE module) and the site "Regulatory monetary valuation of agricultural land" [18], which contains archival maps of agricultural soil groups.

As a result of the decoding, 935 vector polygons were identified, characterizing the erosion processes on arable lands. The total allocated territories are 50.2 $\mathrm{km}^{2}$. This is $2.4 \%$ of the surveyed area.

Here, we should note two important methodological aspects of the eroded soils allocation according to remote sensing. First, the content of organic matter (Corg) in the upper genetic horizon varies within 3-5\% for the studied non-eroded soils. Studies show dependence of the spectral properties of chernozem soils on the content of organic carbon [19], this dependence being of the exponential decay type. The curve levels out at approximately the value of Corg= $3 \%$. Further increase in Corg has very little effect on the soil color and its reflectivity. It follows that soils that differ markedly in the pictures in their color from the background contain considerably less than $3 \%$ organic matter. That is, they lost more than half of the upper humus horizon.

From the viewpoint of such soils classification according to the degree of erosion, they belong to the 
moderately -eroded or heavily eroded soils (FAO, 2006) [20]. Therefore, the figures obtained by us do not include weakly eroded soils, which do not differ in color from modal (non-eroded) soils.

The second aspect is the correctness of the spatial selection of eroded soils.

Both light and dark areas are in the zones of surface erosion manifestation (Fig. 3). It may seem that the overall erosion will be overestimated.

But this is not the case. Figures 9-10 give an example of a detailed field soil survey of one of the linear erosions. The survey was conducted near the village Vasylivske (Nova Vodolaga district, Kharkiv region) in the framework of another research project in 2010.

As part of the study, 18 soil sections were laid. The laying scheme was as follows: 1) 6 sections were laid along the bottom of the runoff basin at a distance of 50 $\mathrm{m}$ from each other, 2) two more sections were laid opposite each of these sections on opposite sides of the basin. The distance between them and the sections at the bottom of the basin was $20 \mathrm{~m}$.

Figs. 9-10 show the depths of humus-rich horizon $(\mathrm{H})$. As we can see, the depth of the horizon ranges from 20 to $100 \mathrm{~cm}$. For comparison, it should be noted that the depth of this horizon for modal (non-eroded) soil in this field is $40 \mathrm{~cm}$.

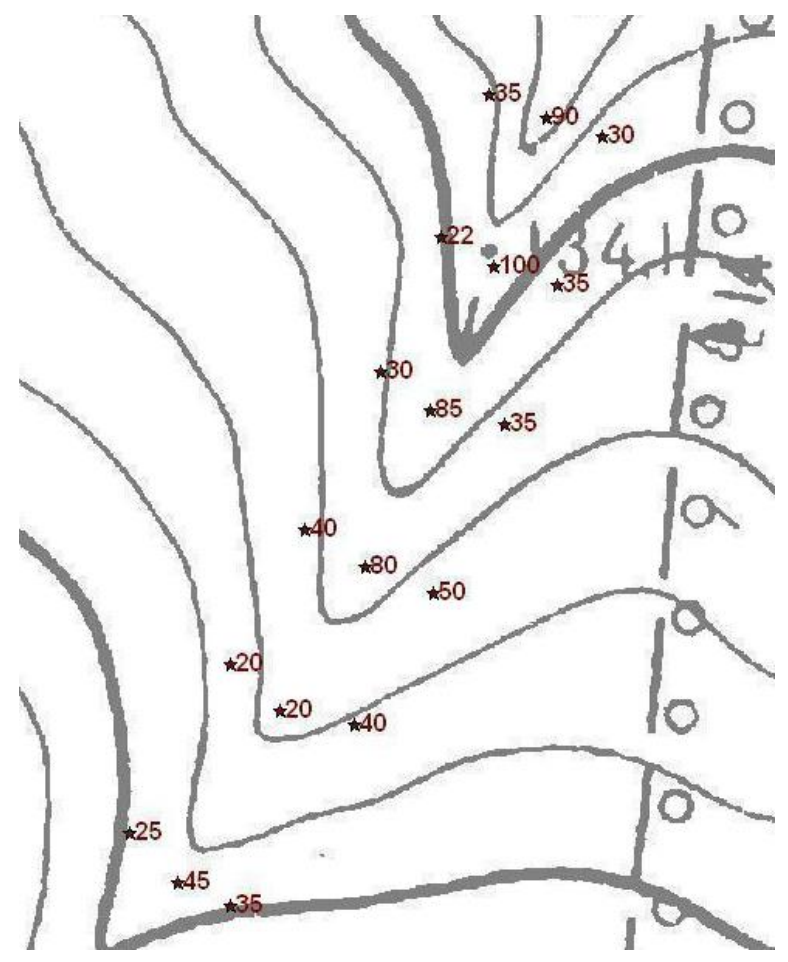

25 - the depth of the upper humus-accumulative genetic horizon

Fig. 9. A fragment of a topographic map showing the locations (marked with asterisks *) of the sampling points and the depths of the humus-rich horizon

Respectively, soils with $\mathrm{H}$ less than $40 \mathrm{~cm}$ according to the existing method of field diagnosis of eroded soils are considered eroded, and with $\mathrm{H}$ greater than $40 \mathrm{~cm}$ - uneroded; in sections placed along the talweg of a temporary water course such soils can be characterized as alluvial. It should be noted that in nature the rates of erosional and depositional processes exhibit both spatial and temporal variability. Consequently, eroded and alluvial soils alternate in some areas. All these soils can be called erosionalluvial (i.e. washed or re-worked) soils.

As we can see (Fig. 10), the areas adjacent to most of the sampling points on both slopes of the basin do not differ in color from modal soils, although they are classified as eroded by the value of $\mathrm{H}$.

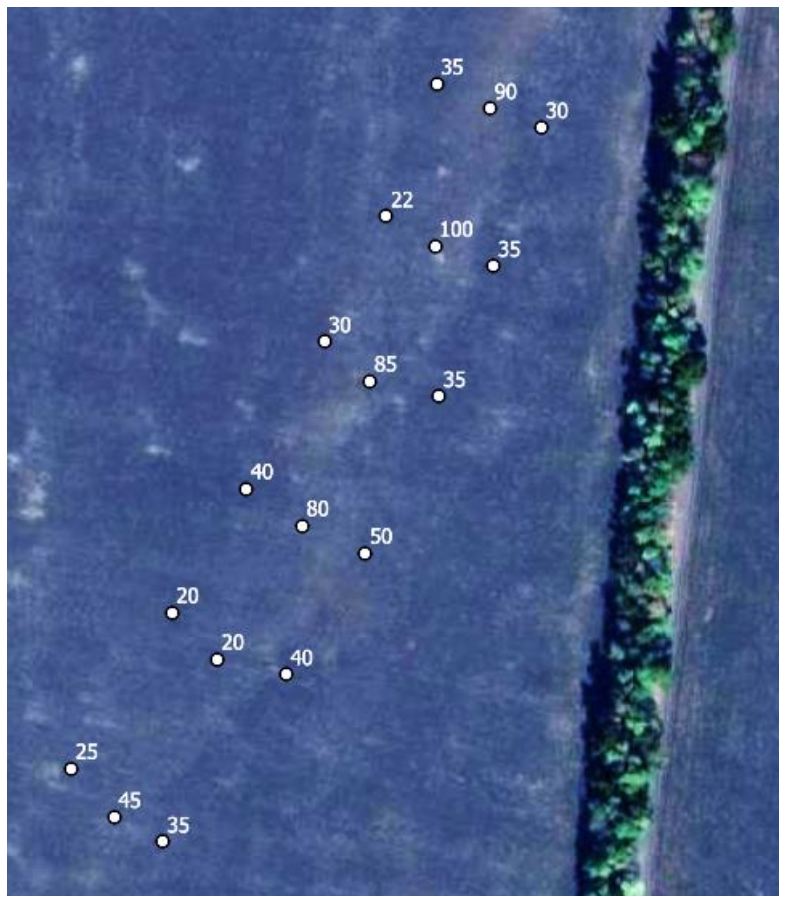

25 - the depth of the upper humus-accumulative genetic horizon

Fig. 10. A snapshot of GoogleEarth (11.10.2018)

Thus, the continuous allocation of areas characterized by a "feathery" image structure as superficially eroded, is justified. The spectral samples collection of eroded lands, created during the research, will be further used to test the method of "computer vision" [21] for automated decoding of space images.

\section{Concluding remarks}

Remote sensing is an uncontested method of real-time monitoring of eroded soils. Automatic interpretation of water erosion manifestations in satellite images is the most attractive option for operational monitoring of erosion. However, despite many attempts to automatically decode erosion all over the world, the technique has not yet been fully developed.

Creation of a technique for the correct automatic decoding is impossible without the development of an algorithm for delineation of areas covered by eroded soils according to a set of decoding signs providing clues for their identification. An important methodological point is also the elimination of decoding errors, which include recognition of various anthropogenic objects and natural heterogeneity of the soil cover as erosion manifestations. 
In our studies, we established a combination of decoding signs to determine the manifestations of linear and surface water erosion features from images. Specific characteristics of the reflected signal in the areas covered by chernozem soils with high humus content makes it possible to correctly identify moderately and heavily eroded soils. Analysis of the Sentinel satellite image allowed us to assess the share of moderately and heavily eroded soils on arable lands within the studied territory at $2.4 \%$ of their total area.

Currently, soil erosion represents one of the most serious environmental problems, and our results are therefore relevant for researchers and practitioners dealing with negative consequences of soil erosion for agriculture, economy and society. The eroded sediment particles alter light penetration and biogeochemical balance of the receiving water courses [22]. Furthermore, suspended sediments adsorb large quantities of pollutants [22], which may then be transported for long distances affecting not only freshwater, but also marine ecosystems. Our study is, therefore, relevant to all these issues. In addition, the methodology presented here will also be of use for a wider range of applications relying on the use of remote sensing data.

\section{Conflict of interest}

The authors declare that there is no conflict of interests regarding the publication of this manuscript. In addition, the ethical issues, including plagiarism, informed consent, misconduct, data fabrication and/or falsification, double publication and/or submission, and redundancy have been completely observed by the authors.

\section{References}

1. S. Bulygin, The Ukrainian Farmer, 6, 46-47 (2015)

2. Outcome document of the Global Symposium on Soil Erosion, FAO, 15-17 May 2019, Rome, Italy (2019)

3. M. Sartoria, G. Philippidis, T. Ferrari, P. Borrelli, E. Lugato, L. Montanarella, P. Panagos, Land Use Policy, 86, 299-312 (2019)

4. M.I. Luleva, H. van de Werff, F. van der Meer, V. Jetten, Chemistry: Bulgarian Journal of Science Education, 21 (5), 748-764 (2012)

5. K.E. Seutloali, T. Dube, O. Mutanga, Phys Chem Earth, 100, 296-304 (2017)

6. A.B. Achasov, A.O. Achasova, Visnyk of V. N. Karazin Kharkiv National University, ser. "Ecology" 944 (6), 20 - 27 (2011)

7. Vågen T-G, Winowiecki LA. Remote Sens. 11(15), 1800 (2019)

8. H. Shahabi, B. Jarihani, S. Tavakkoli Piralilou, D. Chittleborough, M. Avand, O. Ghorbanzadeh, Sensors, 19 (22), 4893 (2019)
9. A. Karami, A. Khoorani, A. Noohegar, S.R.F. Shamsi, V. Moosavi, Environmental and Engineering Geoscience. 21 (2), 101-110 (2015)

10. S.Uchida, Procedia Environ. Sci. 24, 29-34 (2015)

11. K. A. Lukyanchuk, I. P. Kovalchuk, O. M. Pidkova Application of a remote sensing in monitoring of erosion processes, in Proceedings of the Conference "Geoinformatics: Theoretical and Applied Aspects”, 11-14 May 2020, Kiyv, Ukraine (2020)

12. D. Žížala, A. Juřicová, T. Zádorová, K. Zelenková, R. Minařík, Eur. J. Remote Sens. 52, 108-122 (2019)

13. Periodical report on the condition of soils on agricultural land of Ukraine based on the results of the 9th round (2006-2010) of agrochemical survey of lands. (GA "Institute of Soil Protection of Ukraine", 2015)

14. V. Koval, V Natalochka, S. K. Tkachenko, Visnyk of Poltava State Agrarian academy, 3, 84-88 (2013)

15. Soil quality. Methods for determination of organic matter: DSTU 4289:2004. (Derzhspozhyvstandart of Ukraine, 2006)

16. E. I. Karavanova Optical properties of soils and their nature. (2003).

17. M. H. Carr, Philos. Trans. R. Soc. Lond. A 370, 2193-2215 (2012)

18. Ukraine Normative Monetary Land Assessment Portal

19. A. Achasov, A. Achasova, 50North (2017)

20. Guidelines for soil description. Fourth edition. (FAO, 2006)

21. M. Zhu, Y. He, Q. He, International Journal of Geosciences, 10, 1-11 (2019)

22. S. Arthur et al. Blue-green infrastructureperspectives on water quality benefits (CIRIA, 2019) 